\title{
Evidence Against a Specific Effect of Serum from Patients with Cystic Fibrosis on Sodium- Dependent Glucose Transport in the Rat Jejunum
}

\author{
PETER C. WILL, THOMAS F. BOAT, AND ULRICH HOPFER \\ Departments of Anatomy and Pediatrics, School of Medicine, and Developmental Biology Center, Case Western \\ Reserve University, Cleveland, Ohio USA
}

\begin{abstract}
Summary
Sera from patients with cystic fibrosis of the pancreas (CF) and normal human sera were assayed for the ability to inhibit sodiumdependent glucose transport in rat brush-border membrane vesicles. Fresh CF and age- and sex-matched control sera were both inhibitory when compared to physiologic saline. The inhibition by CF serum was $44 \pm 13 \%$ (mean \pm SD) at a final serum concentration of $6.7 \%, 67 \pm 34 \%$ at $10 \%$ serum, and $68 \pm 28 \%$ at $20 \%$ serum. The ratio of the inhibition of CF sera compared to that of control sera was $1.00,0.78$, and 0.93 at $6.7,10$, and $20 \%$ serum concentrations, respectively. Although a slightly greater inhibition by $\mathbf{C F}$ serum was observed at a concentration of $10 \%$, this is probably not significant because no difference could be detected at a concentration of $\mathbf{2 0} \%$ serum. Glucose transport in the presence of serum was sensitive to phlorizin indicating that the residual glucose transport was proceeding by the sodium-dependent glucose transport system. These findings suggest that CF serum does not specifically inhibit the sodium-dependent glucose transport system.

The intravesicular space accessible to glucose was reduced in the presence of $\mathrm{CF}$ or control serum. Fresh $\mathrm{CF}$ serum was 1.4 times more effective than fresh control serum $(P<0.01)$. The presence of substantial vesicle-shrinking activity in control serum indicates that this activity cannot be considered specific for CF.
\end{abstract}

Speculation

The CF specific factor that inhibits sodium transport may be effective only with epithelial tissues capable of transporting sodium chloride against high concentration gradients, such as the epithelia of the ducts of the saliva and sweat glands, the colon, the distal renal tubules, and the renal collecting tubules.

Considerable evidence has been reported that a factor (or factors) in the sweat or saliva from patients with CF inhibits sodium reabsorption by specific epithelia $(11,21,23-25,33,37)$. This factor has not been isolated, principally because of its lability and the lack of a convenient and reliable assay system. The retrograde perfusion assay of the rat parotid, for example, is quite difficult $(5,37,42)$. Recently a new assay was suggested that involved measuring the inhibition of the intestinal glucose-dependent sodium transport by CF serum (1). The sodium transport was measured electrically as the short-circuit current, and the assay was potentially accurate and rapid. Unfortunately, additional observations noted that the inhibitory activity was not unique to CF sera, but was also present in control sera (2).

In other studies employing intestinal rings, it was found that the 60-min uptake of glucose analogs was inhibited more by $\mathrm{CF}$ sera than by normal sera $(3,7)$. As these experiments were not performed to study transport rates strictly, the results do not necessarily indicate an effect of CF-serum on membrane transport of glucose. The $60-\mathrm{min}$ uptake of the glucose analogs represents the steady state levels of accumulation. These steady state levels can be affected by many different factors, particularly those that interfere with metabolism, energetics, cell viability, and plasma membrane integrity.

Nevertheless, the previously mentioned studies suggested that CF sera might inhibit sodium-dependent glucose transport in the small intestine. In order to directly assess this effect, the ability of $\mathrm{CF}$ and control sera to inhibit sodium-dependent glucose transport in rat jejunal brush-border membrane vesicles was examined. This is a well established system for measuring nonelectrolyte and electrolyte transport, and has been invaluable for characterizing sodium and sodium-dependent transport systems of the intestinal brush-border membrane $(17,20,28,34)$. Due to the stoichiometric coupling between sodium and glucose during transport $(28,32)$, inhibition of the glucose transport system might be expected to affect equally the sodium and glucose fluxes. Whereas sodium is taken up by glucose-independent and glucose-dependent pathways, glucose transport by brush-border membrane vesicles occurs predominantly via cotransport with sodium. Therefore, the uptake of glucose was chosen to evaluate the effects of sera on the sodiumdependent glucose transport system.

\section{MATERIALS AND METHODS}

\section{PATIENTS AND CONTROL SUBJECTS}

Patients contributing serum for this study were from the Cleveland Cystic Fibrosis Center. At the time serum was collected, none had received antibiotics or pharmacologic agents other than pancreatic enzymes and vitamins for at least $24 \mathrm{hr}$. Their clinical scores ranged from 46-84 (12). Control donors were either patients hospitalized for nonpulmonary, noninflammatory conditions, student volunteers, or young laboratory personnel. CF patients and normal donors were matched for sex and for age as much as possible. Informed consent was obtained from patients and volunteers contributing serum.

\section{SERUM COLLECTION AND TREATMENT}

Venous blood was collected into plastic tubes without anticoagulants. The blood was clotted at $37^{\circ}$ (typically 3-20 min) and the clot was separated by centrifuging at $2100 \times \mathrm{g}$ for $15 \mathrm{~min}$ at $4^{\circ}$. The serum was collected and stored at $0-4^{\circ}$ in polyethylene tubes. Plastic equipment was used for all manipulations. Unless otherwise indicated, the serum samples were assayed for transportinhibiting activity within $56 \mathrm{hr}$ of collection (four within $8 \mathrm{hr}$ of collection). Hemolyzed samples were discarded. Serum protein and glucose concentrations were measured using established methods $(22,41)$. 
ASSAY OF SODIUM-DEPENDENT GLUCOSE TRANSPORT

Jejunal brush-border membrane vesicles were prepared from male Sprague-Dawley rats by the method of Schmitz et al. (29) as modified in this laboratory (34). Membrane purification was routinely evaluated by the enrichment of sucrase (E.C.3.2.1.48), a marker for the intestinal brush border membrane (20); the purification observed in nine experiments was $18 \pm 5$-fold. Membrane protein was measured by the method of Bensadoun and Weinstein (6). Membrane vesicles, suspended in $0.1 \mathrm{M}$ D-mannitol and 1 $\mathrm{mM}$ Tris-Hepes $\mathrm{pH} 7.5$, were preincubated with $0.11 \mathrm{M}$ sodium chloride, $20 \mu \mathrm{g} / \mathrm{ml}$ monactin and either physiologic saline (control) or dilutions of serum for $15 \mathrm{~min}$ at $25^{\circ}$. The ionophore monactin was added to prevent changes of the membrane potential during glucose transport $(17,28)$. Unless otherwise indicated, serum treatments were examined in duplicate or triplicate at final concentrations of $6.7,10$, and $20 \%(\mathrm{v} / \mathrm{v})$ in physiologic saline. Dglucose uptake was initiated by addition of the labeled substrate ( $10 \mathrm{mM}$ at a specific activity of $3 \mathrm{Ci} / \mathrm{mole}$ ) and measured at frequent intervals using the membrane filtration assay (28). Virtually all of the glucose uptake is accounted for by transport into the intravesicular space (43). Rates were obtained at $25^{\circ}$ as the reciprocal of the time required for half maximal uptake into the intravesicular space. This method has been shown to give reliable estimates of the D-glucose transport rate in isolated brush-border membrane vesicles (18). Uptake of D-glucose by the sodiumdependent transport system was evaluated by including $100 \mu \mathrm{M}$ phlorizin, which is a specific inhibitor of this system $(17,20)$. The D-glucose concentration was $1 \mathrm{mM}$ in these experiments.

Transport rates of the membrane vesicles vary somewhat between membrane preparations due to animal differences or other uncontrollable factors. Consequently, the data from serum-treated vesicles are expressed as the fractions of the equilibration rates of the saline-treated vesicles. Glucose transport into paired control and $C F$ serum-treated vesicles was measured on the same membrane preparation at the same time. Intravesicular space was determined from the equilibrium uptake of D-glucose after $20-40$ min (average $25 \mathrm{~min}$ )

Sample variability is given as the mean $\pm \operatorname{SD}(n)$. Differences between groups were evaluated by the paired Student's $t$ test where $P<0.05$ was considered significant (40).

\section{MATERIALS}

D- $\left[1-{ }^{3} \mathrm{H}\right]$ glucose was obtained from the New England Nuclear Corp., Boston, MA. D- $\left[{ }^{14} \mathrm{C}(\mathrm{U})\right] \mathrm{glucose}$ was purchased from Schwarz-Mann, Orangeburg, NY. Monactin was a gift of CibaGeigy, A.G., Basel, Switzerland. Male Sprague-Dawley rats (strain number Zml:ZM(SD)BR) were from Zivic-Miller, Laboratories, Inc., Allison Park, PA. Other reagents and chemicals were reagent grade.

\section{RESULTS}

The presence of serum decreased the initial and final D-glucose uptake by vesicles of isolated brush border membranes (Fig. 1). The lower equilibrium uptake indicates a loss of intravesicular space accessible to glucose. If the reduced space is due to vesicle shrinkage and the ratio of surface area to intravesicular space is increased, the apparent transport rate that is estimated as the reciprocal of the half-time $\left(\mathrm{T}^{1 / 2}\right)$ in glucose equilibration must be corrected for the change in space. In this case (Model I), the transport rates measured in the presence of serum have to be normalized to the same surface area to space ratio as those measured in saline. Therefore, the transport rates were corrected by multiplying the observed $\mathrm{T}_{1 / 2}{ }^{-1}$ with the value of the reduced space expressed as fraction of the same vesicles in saline (for details, see Ref. 44). Calculations based on Model I give a lower limit for the relative transport rates (for upper limits, see Ref. 44).

The effects of $C F$ and control sera on the glucose transport rates, calculated according to Model I, are shown in Figure 2 and summarized in Table 1 . The data indicate that serum significantly inhibited glucose transport at each of the concentrations examined.

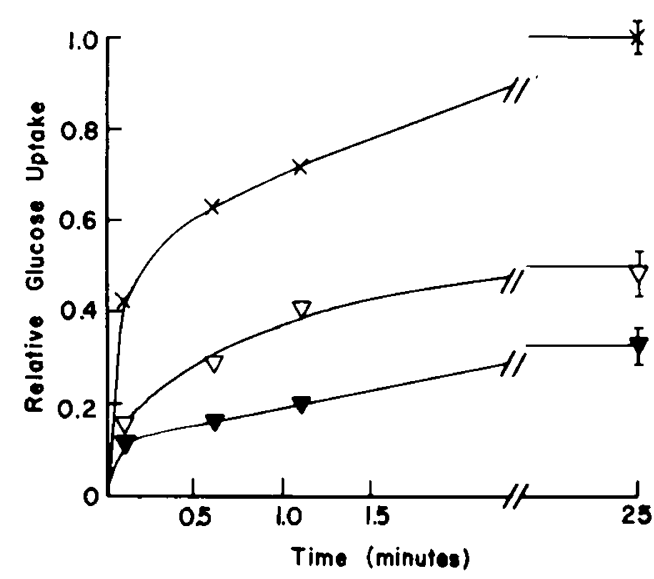

Fig. 1. Effect of serum on glucose uptake by membrane vesicles. Membrane vesicles were preincubated with $20 \%$ control (open symbols) or CF (filled symbols) serum for $15 \mathrm{~min}$ before addition of $10 \mathrm{mM}$ labeled $\mathrm{D}$ glucose. Uptake of glucose was measured as described in the Methods, and normalized to the uptake of the saline control (crosses) at equilibrium ( $14.1 \pm 0.8 \mathrm{nmole} / \mathrm{mg}$ membrane protein $(n=4)$ ). The equilibrium values were measured in triplicate and are plotted as the mean $\pm \mathrm{SD}$. Both the control donor and the CF patient were 13-yr-old males.

At 6.7 and $20 \%$ serum, there was no significant difference between $\mathrm{CF}$ and control serum, whereas at $10 \%, \mathrm{CF}$ serum was slightly more inhibitory than control serum. The inhibition of glucose transport by $10 \% \mathrm{CF}$ serum did not correlate with the clinical scores of the patients. Therefore, the observed inhibition is not related to the severity of the disease.

Although the difference in inhibitory potency between CF and control serum at $10 \%$ is statistically significant $(P<0.025)$ the factor(s) causing the inhibition cannot be considered CF-specific as a difference was observed only at the intermediate concentration. Even this difference may be artifactual due to the space correction employed. The uncorrected transport rates were essentially identical in the presence of CF and control serum (44).

Attempts to correlate the inhibition by $C F$ and control serum with either age or sex only revealed the absence of such correlations (see Fig. 2). Furthermore, the inhibition did not correlate with the time between the collection of the serum and the transport measurements, or the protein and glucose concentrations in the serum (45).

Serum apparently did not affect the transport mechanism for glucose as judged by sensitivity of the glucose transport to the specific inhibitor phlorizin. For example, in the presence of $6.7 \%$ CF serum, the rate of glucose uptake was decreased $60 \%$ by 0.1 $\mathrm{mM}$ phlorizin.

The reasons for the loss of intravesicular space in the presence of serum (Fig. 1) are not clear. Replacement of human serum with either dialyzed human or bovine serum albumin resulted in only a slight decrease of vesicle volume so that the colloid-osmotic pressure of serum can be eliminated as a major cause. To explore whether this effect is CF specific, the data on the equilibrium uptake of glucose was analyzed in more detail. The concentration of serum required for a $50 \%$ reduction of the glucose accessible space of saline-treated vesicles was determined from plots of the equilibrium values versus serum concentration (not shown). The results (Table 2) indicate that fresh $\mathrm{CF}$ serum was significantly more effective than fresh control serum in reducing the space accessible to glucose. However, the activity in serum was increased by freezing and a comparison of frozen CF sera with frozen control sera indicated a similar concentration of this activity in both groups (Table 2). It is thus unlikely that the serum activity that reduced the equilibrium space can be attributed to a $\mathrm{CF}$ factor because it was present in normal serum. The manifestation of the vesicle shrinking activity in fresh CF serum may be due to other factors in serum which are destroyed by freezing. The substance(s) in normal and CF serum that reduced the equilibration space was dialysable $(22 \mathrm{hr}$ against 100 volumes of saline at 


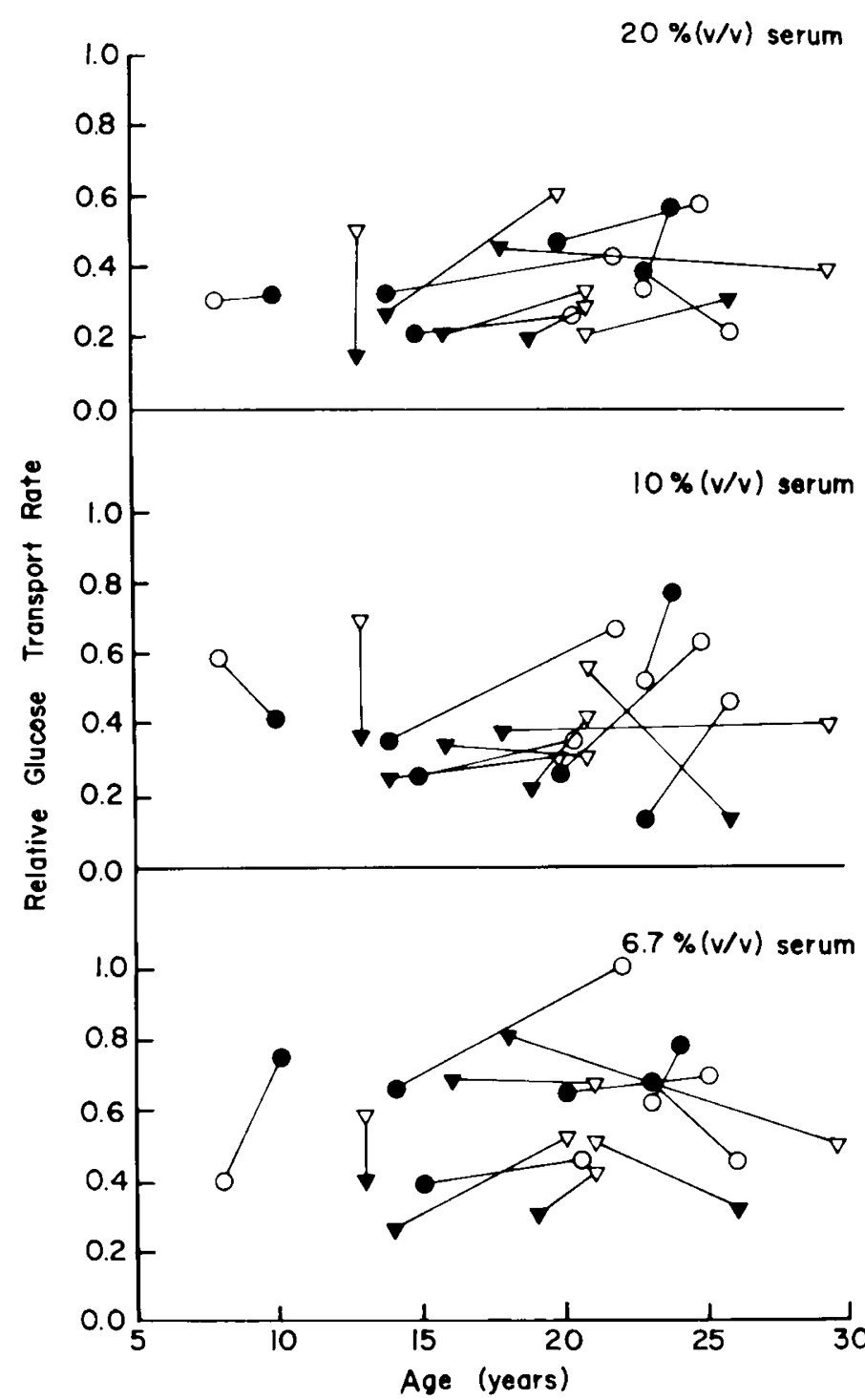

Fig. 2. The effect of $C F$, sex, and age on serum inhibition of the glucose uptake rate by membrane vesicles. $\mathbf{Q}, \nabla=\mathrm{CF}$ serum; $O, \nabla=$ normal control serum; $\bullet, O=$ females; $\nabla, \nabla=$ males. Glucose uptake was normalized to the uptake rate observed in saline-treated vesicles measured with the same membrane preparation as described in the text. The time for $50 \%$ glucose equilibration of saline-treated vesicles was $21 \pm 6 \mathrm{sec}(n$ $=7$ ) for the different preparations used in this study. The coefficient of variance observed with the individual serum concentrations was generally $15 \%$.

$\left.2^{\circ}\right)$, stable to heat $\left(56^{\circ}\right.$ for $\left.30 \mathrm{~min}\right)$, and tolerated freezing and treatment with powdered glass $\left(25 \%\right.$ by weight at $2^{\circ}$ for $18 \mathrm{hr}$ ). These properties are different from those of previously described CF factors $(1,24,25,42)$ and contrast with activity inhibiting the rate of glucose transport which although dialyzable is heat labile (conditions the same as those previously discussed).

\section{DISCUSSION}

Transport inhibitory activities have been reported in CF saliva or sweat and in CF serum. The former activity inhibits sodium reabsorption in the ducts of the saliva and sweat glands, and although well accepted as a characteristic of CF, this activity has not been purified or identified because of the lability and difficulty of its assay $(23,24,37,42)$.

Another CF-specific serum activity, the ciliary dyskinesia factor, has been partially purified $(4,8,38,39)$, however, there is no known connection between this activity and the CF transport inhibitory activities in CF saliva, sweat, or serum. Indeed, the binding of the ciliary dyskinetic activity to $C 4(8,39)$ suggests that
Table 1. Effect of serum on the relative uptake rate of glucose by membrane vesicles 1

\begin{tabular}{ccccl}
\hline $\begin{array}{c}\text { Serum } \\
\text { concen- } \\
\text { tration } \\
\%(\mathrm{v} / \mathrm{v})\end{array}$ & Control serum & CF serum & $\begin{array}{c}\text { Number } \\
\text { of pairs }\end{array}$ & Significance \\
\cline { 2 - 4 } 6.7 & $0.56 \pm 0.17$ & $0.56 \pm 0.20$ & 12 & $P>0.8$ \\
10.0 & $0.48 \pm 0.12$ & $0.33 \pm 0.17$ & 12 & $P<0.025$ \\
20.0 & $0.37 \pm 0.13$ & $0.32 \pm 0.13$ & 12 & $P>0.3$ \\
\hline
\end{tabular}

${ }^{1}$ The rates were determined as reciprocals of the times for $50 \%$ equilibration from plots as in Figure 1. They were normalized to the same ratio of vesicle surface area to volume as that of saline-treated vesicles (see Results). Saline-treated vesicles have a relative rate of 1 .

Table 2. Effect of control and CF sera on the intravesicular space accessible to glucose $e^{1}$

Serum concentration $\%(\mathrm{v} / \mathrm{v})$ causing $50 \%$ reduction of the glucose accessible space

\begin{tabular}{lcc}
\cline { 2 - 3 } \multicolumn{1}{c}{ Serum } & Fresh serum & Frozen serum \\
\hline Normal & $19.9 \pm 4.8(12)$ & $9.2 \pm 1.9(8)$ \\
CF & $14.6 \pm 4.6(12)$ & $9.3 \pm 3.2(8)$ \\
Significance & $P<0.01$ & $P>0.90$ \\
\hline
\end{tabular}

${ }^{1}$ The glucose accessible space in the saline-treated vesicles was $0.98 \pm$ $0.29 \mu \mathrm{l} / \mathrm{mg}$ membrane protein $(n=18$; space $=$ equilibirium uptake divided by the medium concentration of D-glucose). Serum concentrations reducing this space were estimated by interpolating from plots of equilibrium values obtained at various serum concentrations (see text). The number of serum pairs is given in the parentheses.

it may be more related to secondary immunologic complications of $\mathrm{CF}$ than to the transport inhibitory activity that is a primary characteristic of CF $(11,24)$.

CF serum has been reported to inhibit sodium or sodiumdependent nonelectrolyte transport in the rat small intestine more than control serum $(1-3,7,16)$. The transport inhibitory activities present in CF saliva and CF serum are similar in that they inhibit sodium or sodium-dependent nonelectrolyte transport systems of epithelial tissues. However, there is no evidence that the same agent is responsible for the inhibitory effects of the two fluids. Actually, very different types of transport systems are probably involved in sodium reabsorption by the ducts of saliva and sweat glands, cotransport of glucose and sodium by the small intestine, and nonelectrolyte-independent sodium absorption by the small intestine. Hence, it is possible that different types of agents are responsible for inhibition of sodium transport via the different routes and that an assumed or implied identity of the factors is not warranted. Furthermore, the inhibition of sodium reabsorption by CF saliva or CF sweat is a well established phenomenon which clearly relates to the pathophysiology of abnormal sodium concentrations in the sweat and saliva from patients with CF (11, 23-25). However, it is not obvious that the inhibition of glucosedependent short-circuit current (16) or the inhibition of the steady state uptake of nonelectrolytes in the intestine are related to the disease. The objective of this study was to extend the work of Araki et al. $(1,2)$ and attempt to detect a clearly defined membrane level interaction of $\mathrm{CF}$ serum with the sodium-dependent glucose transport system in the small intestine.

The results of this study generally confirm previous observations that indicated that the transport inhibitory activity in human serum is not specific for either the transported solute or CF $(5,9$, $10,27,35,36)$, but are at variance with the reports that stimulated this investigation $(1,3,7,16)$. These discrepancies in experimental findings may be a result of either the experimental methods (see Materials and Methods) or the specific patients and controls included in the various studies. Patient and control selection is a crucial point in investigations of this type as $C F$ patients may differ from controls for reasons not related to the primary defect in CF. For example, variations may be caused by specific and 
nonspecific medication or by secondary changes that occur during the course of a chronic disease. In this study a concerted effort was made to control these factors.

Gilmore et al. (16) recently reported results similar to those of Araki et al. (2) when CF serum was added to the mucosal side of the jejunum. However, in contrast to the initial work of Araki et al. (1), when CF serum was added to the serosal side of the tissue, no effect was observed (16). The time course of CF serum effects on the electrical fluxes across the small intestine is complex, with inhibition after a rapid stimulation. The inhibition is also relatively slow with a half-time of $\sim 9 \min (16)$. These latter observations suggest that the effect of serum is complex and involves more than a simple transport site-inhibitor interaction.

The failure to observe any CF-specific transport inhibitory activity in CF sera may not necessarily indicate the absence of such an activity, but may be due to either a requirement for the intact enterocyte for activity, or more likely, may be due to the fact that the small intestine is a poor choice of tissue for such studies. The CF inhibitory activity is a well established phenomena in the ducts of the sweat gland and the saliva gland $(11,21,23$, 37). These tissues and the large intestine (14), in contrast to the small intestine, are low-conductance epithelia with electrically "tight" junctions (15). The routes of electrolyte transport in lowconductance epithelia appear to be qualitatively different from other epithelia as shown not only by the low conductance, but also by relatively high transepithelial potential differences, the capability of producing hypotonic luminal solutions, regulation of electrolyte transport by aldosterone, and sensitivity of the sodium transport to the diuretic amiloride $(26,30,31)$. Future investigations of CF factor activity on electrolyte transport should use low conductance epithelial tissues in order to increase the probability of obtaining meaningful results.

\section{CONCLUSION}

The activity in human serum that inhibits sodium-dependent glucose transport by rat brush-border membrane vesicles is present at the same concentration in normal and CF serum. The activity in fresh human serum that reduces the intravesicular volume accessible to glucose is elevated in fresh CF serum, but this activity is not specific for CF as it is present at the same concentration in frozen $\mathrm{CF}$ and control sera.

\section{REFERENCES AND NOTES}

I. Araki, H., Field, M., and Shwachman, H.: A new assay for cystic fibrosis factor: effects of sera from patients with cystic fibrosis in the in vitro electrical properties of rat jejunum. Pediat. Res., 9: 932 (1975).

2. Araki, H., Field, M., and Shwachman, H.: A new assay for cystic fibrosis factor: effect of sera from patients with cystic fibrosis on the in vitro electrical properties of rat serum. (7th International Cystic Fibrosis Congress, Abstracts of Medical Sessions, Paris, France, p. 28. 1976).

3. Arvanitakis. S.. Mangos, J.. McSherry, N. R., and Rennert, O.: Effect of polyamines and cystic fibrosis serum on glucose transport. Tex. Rep. Biol. Med., 34: 175 (1976).

4. Barnett, D. R., Schanfield, M. S., McCombs, M. L., and Bowman, B. H.: Isoelectric focusing and IgG allotyping of the serum fraction containing the cystic fibrosis ciliary inhibitor. Tex. Rep. Biol. Med.. 31: 709 (1973).

5. Benke, P. J., Herrick. N., and Pitot, H. C.: Studies on basic charged molecules and cell membranes in cystic fibrosis. Proc. Soc. Exptl. Biol. Med., 137: 1283 (1971).

6. Bensadoun, A., and Weinstein, D.: Assay of proteins in the presence of interfering materials. Anal. Biochem., 70: 241 (1976).

7. Brown, G. A., Oshin, A., Goodchild, M. C., and Anderson, C. M.: Inhibition of sugar transport by plasma from cystic fibrosis patients. Lancet. 2: 639 (1971).

8. Conod. E. J., Conover, J. H., and Gaerlan, P.: Separation of serum cilliary dyskinesia substances from cystic fibrosis subjects. Pediatr. Res., 11: 45 (1977).

9. Desjeux, J. F., and Morin, C. L.: The effect of saliva and serum of cystic fibrosis on alanine in vitro intestinal transport. (European Pediatric Society Meeting. Abstracts, Stockholm. Sweden, 1970 p. 10).

10. Desjeux, J. F., Tannenbaum, C.. and Curran, P. F.: Effects of normal human serum on electrolyte transport by rabbit ileum. (Cystic Fibrosis Club Abstracts, 15th annual meeting, 1974 p. 35 ).

11. di Sant'Agnese, P. A., and Davis, P. B.: Research in cystic fibrosis. N. Engl. J. Med., 295: 481 (1976).

12. Doershuk, C. F., Matthews, L. W., Tucker, A. S., Nudelman, H., Eddy, G., Wise, M., and Spector, S.: A 5-year clinical evaluation of a therapeutic program for patients with cystic fibrosis. J. Pediat., 65: 677 (1964).

13. Doggett. R. G. and Harrison, G. M.: Cystic fibrosis: reversal of ciliary inhibition in serum and saliva by heparin. Tex. Rep. Biol. Med., 31: 685 (1973).

14. Frizzell, R. A., Koch, M. J., and Schultz, S. G.: Ion transport by rabbit colon. 1 . Active and passive components. J. Membr. Biol., 27: 297 (1976).

15. Fromter, E., and Diamond, J.: Route of passive ion permeation in epithelia. Nature New Biol., 235: 9 (1972).

16. Gilmore, J. P., Davis, M., and Gibbs, G. E.: Influence of cystic fibrotic and heterozygous serum on rat jejunum. Proc. Soc. Exptl. Biol. Med.. 157: 70 (1978).

17. Hopfer, U.: Diabetes mellitus: changes in the transport properties of isolated intestinal microvillous membranes. Proc. Nat. Acad. Sci. USA, 72: 2027 (1975).

18. Hopfer, U.: Kinetics of $\mathrm{Na}^{+}$-dependent D-glucose transport. J. Supramol. Struct., 7: p. 1 (1977).

19. Hopfer, U., Nelson, K., Perrotto, J., and Isselbacher, K. J.: Glucose transport in isolated brush border membrane from rat small intestine. J. Biol. Chem., 248: 25 (1973).

20. Hopfer, U., Sigrist-Nelson, K., and Murer, H.: Intestinal sugar transport: studies with isolated plasma membranes. Ann. N.Y. Acad. Sci., 264: 414 (1975)

21. Kaiser, D., Drack, E., and Rossi, E.: Inhibition of net sodium transport in single sweat glands by sweat of patients with cystic fibrosis of the pancreas. Pediatr. Res., 5: 167 (1971).

22. Lowry, O. H., Rosebrough, N. J., Farr, A. L.. and Randall. R. J.: Protein measurement with the folin phenol reagent. J. Biol. Chem., 193: 265 (1951).

23. Mangos. J. A.: Microperfusion study of the sweat gland abnormality in cystic fibrosis. Tex. Rep. Biol. Med.. 31: 651 (1973).

24. Mangos. J. A.. and McSherry, N. R.: Sodium transport: inhibitory factor in sweat of patients with cystic fibrosis. Science, 158: 135 (1967).

25. Mangos, J. A., McSherry. N. R., and Benke. P. J.: A sodium transport inhibitory factor in the saliva of patients with cystic fibrosis of the pancreas. Pediatr. Res., l: 436 (1967).

26. Meng, K.: Comparison of the local effects of amiloride hydrochloride on the isotonic fluid absorption in the distal and proximal convoluted tubule. Pflugers Arch. Eur. J. Physiol.. 357: 91 (1975).

27. Morin, C. L., Desjeux, J. F., and Authier, L.: Effect of saliva and serum from patients with cystic fibrosis on intestinal uptake of amino acids in rat. Biomed. Express, 19: 133 (1973).

28. Murer, $\mathrm{H}$., and Hopfer, U.: Demonstration of electrogenic $\mathrm{Na}^{+}$-dependent Dglucose transport in intestinal brush border membranes. Proc. Nat. Acad. Sci. USA. 7I: 484 (1974).

29. Schmitz, J., Preiser, H., Maestracci, D., Ghosh, B. K., Cerda, J. J., and Crane. R. $\mathrm{K}$.: Purification of the human intestinal brush border membrane. Biochim. Biophys. Acta, 323: 98 (1973).

30. Schneyer, L. H.: Amiloride inhibition of ion transport in perfused excretory duct of rat submaxillary gland. Am. J. Physiol., 219: 1050 (1970).

31. Schneyer, L. H., Young, J. A., and Schneyer, C. A.: Salivary secretion of electrolytes. Physiol. Rev.. 52: 720 (1972).

32. Schultz. S. G., and Curran, P. F.: Coupled transport of sodium and organic solutes. Physiol. Rev., 50: 637 (1970).

33. Shapiro, B. L., Smith, Q. T., and Warich. W. J.: Serum glutathione reductase and cystic fibrosis. Pediatr. Res.. 9: 885 (1975).

34. Sigrist-Nelson, K., Murer, H., and Hopfer, U.: Active alanine transport in isolated brush border membranes. J. Biol. Chem., 250: 5674 (1975)

35. Tannenbaum, C.. Desjeux, J. F., and Martin. D. W.: Inhibition of uptake of galactose by isolated rabbit ileum following in vivo incubation with human serum. Fed. Proc., 36: 360 (1977)

36. Taussig, L. M. and Gardner, J. D.: Effects of saliva and plasma from cystic fibrosis patients on membrane transport. Lancet. I: 1367 (1972).

37. Taylor, A., Mayo, J. W., Boat, T. F., and Matthews, L. W.: Standardized assay for the sodium reabsorption inhibitory effect and studies of its salivary gland distribution in patients with cystic fibrosis. Pediatr. Res., 8: 861 (1974).

38. Wilson, G. B., and Fudenberg. H. H.: Ciliary dyskinesia factors in cystic fibrosis and asthma. Nature, 266: 463 (1977).

39. Wilson. G. B., and Fudenberg, H. H.: Studies on cystic fibrosis using isoelectric focusing. IV. Distinction between ciliary dyskinesia activity in cystic fibrosis and asthmatic sera and association of cystic fibrosis protein with the activity in cystic fibrosis serum. Pediatr. Res., 11: 317 (1977).

40. Zar, J. H.: Biostatistical Analysis. Pp. 121-124 (Prentice-Hall, Inc., Englewood Cliffs, NJ 1974)

41. Glucose Stat-Pack, cat. No. 869204, Calbiochem Glucose Reagents (1974). Doc No. L 03019, Calbiochem, 10933 N. Torrey Pines Road, La Jolla, CA 92037.

42. Guidance-Action-Projection (GAP) Conference: Polyamines. January 28-30. 1976, Bethesda, MD, Cystic Fibrosis Foundation Report MED-P-46.

43. Binding of glucose to the membrane vesicles is negligible $(<5 \%)$ when compared to the total uptake $(18)$. Binding of glucose to serum proteins under the conditions of the uptake experiments is less than $3 \%$ of the total and glucose binding to the filters is less than $1 \%$ of the total glucose uptake

44. The $T^{1 / 2}$ for a given vesicle is proportional to the ratio of the intravesicular space to surface area. A decrease in the intravesicular space of a vesicle population can be associated with a change in this ratio. Two extreme situations are conceivable: 1 ) the ratio decreases proportional to the decrease of intravesicular space (Model I) because the vesicles shrink without a loss of functionally active surface area. 2) The ratio remains unchanged (Model II) because the loss of intravesicular space is accompanied by the corresponding loss of surface area, i.e. the number of functionally active vesicles decreases. Calculations of transport rates based on measurements of $T_{1}$, have to be corrected for the geometry-dependent changes if Model $I$ is assumed. Therefore, the (corrected transport rate $)_{m e}=\left(T_{1 / 2}\right)_{m e}^{-1} \times(\text { space })_{s e} \times(\text { space })_{m}{ }^{-1}$ whereby the subscript se refers to the experimental condition (type and amount of serum) and sa to glucose uptake in physiologic saline; the intravesicular spaces are assumed to be proportional to the equilibrium uptakes. Because of the correction, the 
calculated transport rates based on Model I give the lower limits of the true rates. If the ratio of the intravesicular space to the surface area remains constant, then the $T_{1 / 2}$ should be independent of the intravesicular space (Model II). The reciprocal of the $T_{1 / 2}$ would be an estimate of the relative transport rates and could be used to compare the effects of CF and control serum on glucose transport (17). Model II gives an upper limit for the relative glucose transport rate. Using Model II, there was no significant difference between the rates in the presence of control or CF serum

\begin{tabular}{|c|c|c|c|c|}
\hline \multirow{2}{*}{$\begin{array}{l}\text { Serum con- } \\
\text { centration }\end{array}$} & \multicolumn{2}{|c|}{ Relative glucose uptake rate } & \multirow{2}{*}{$\begin{array}{l}\text { Number } \\
\text { of pairs }\end{array}$} & \multirow{2}{*}{$\begin{array}{c}\text { Significance } t \\
\text { test }\end{array}$} \\
\hline & Control serum & CF serum & & \\
\hline $6.7 \%$ & $0.75 \pm 0.20$ & $0.78 \pm 0.26$ & 12 & $P>0.6$ \\
\hline $10 \%$ & $0.75 \pm 0.22$ & $0.60 \pm 0.23$ & 12 & $P \sim 0.1$ \\
\hline $20 \%$ & $0.75 \pm 0.22$ & $0.76 \pm 0.25$ & 12 & $P>0.7$ \\
\hline
\end{tabular}

Copyright (C) 1979 International Pediatric Research Foundation, Inc. $0031-3998 / 79 / 1310-1129 \$ 02.00 / 0$
45. Protein and glucose concentrations in both $C F$ and normal sera were in the normal range. Protein $(\mathrm{g} / \mathrm{dl}): \mathrm{CF}=7.7 \pm 0.7$ (12): Control $=7.4 \pm 0.6$ (12). Glucose $(\mathrm{mg} / \mathrm{dl}): \mathrm{CF}=66 \pm 30(12) ;$ Control $=79 \pm 21$ (12)

46. The authors thank Ms. Clara E. Gulyas, Ms. Dorene M. Tarves, Ms. Katherine T. Schmeidler, Mr. David W. Metcalf, and Mr. Rhea G. Groseclose for their technical assistance. The illustrations were preoared by Ms. Diane J. Kastelic.

47. This research was supported by grants from the United States Public Health Service (number AM-08305) and from the Cystic Fibrosis Foundation. Cleveland Chapter. Dr. Hopfer is recipient of a Research Career Development Award (Public Health Service Grant number I KO4 AM00199).

48. Requests for reprints should be addressed to: Ulrich Hopfer, M. D., Ph.D., Department of Anatomy, Case Western Reserve University. Cleveland, $\mathrm{OH}$ 44106 (USA).

49. Received for publication August 30, 1977

50. Accepted for publication October 9, 1978. 